\title{
Nova voz da ficção portuguesa: Dulce Maria Cardoso
}

Marlise Bridi, USP

\begin{abstract}
A Merinho
"Pois que toda a literatura é uma longa carta a um interlocutor invisível, presente, possível ou futura paixão que liquidamos, alimentamos ou procuramos."
\end{abstract}

Novas Cartas Portuguesas

É muito raro, a partir de minha concepção de crítica, que faça uso das declarações do autor. Ou seja, trazer à baila as palavras de um autor acerca de sua própria obra parece-me uma atitude algo herética e temerária.

Entretanto, no caso particular de Dulce Maria Cardoso, será justamente por suas palavras, em uma entrevista, que iniciarei. Como logo se verá, conclamo-as em favor de uma tese (ainda que pequenina) que aqui pretendo apresentar:

Espero pelo tempo em que não existam perguntas ao escritor. Em que a obra seja suficiente, por si, outra vez, como já foi noutros tempos. É disso que tenho esperança, em que o escritor como fazedor e as suas opiniōes não tenham importância. O que tenho para dizer está nos livros, e nas personagens que me aparecem. Venham de onde vierem.

O texto foi retirado da entrevista concedida a Pedro Sena-Lino, no Jornal O Público,
Suplemento Literário "Mil Folhas", de 9 de abril de 2005.

Considero as palavras que acabo de reproduzir muito corajosas. Sobretudo nos dias atuais em que, como uma espécie de Midas pós-moderno, num mundo excessivamente marcado pela exterioridade, pela espetacularização e pelo público, os escritores cada vez mais são vistos como celebridades e o seu valor medido em centenas de milhares de exposições de toda ordem e em todos os lugares.

Em outras palavras, a declaração de Dulce Maria Cardoso poderia ser compreendida, por algum desavisado, como uma espécie de afronta aos todos poderosos meios de comunicação e divulgação, como também, por conseqüência, das leis do mercado e da mídia (ainda mais poderosas).

Entretanto, é quase uma benção e eu diria mesmo um milagre (se a palavra não 
lhes soasse tão pouco acadêmica - que, de resto, sou pouco) que um escritor pense como esta pensa. Dá-nos, aos leitores e aos críticos, o consentimento explícito e tácito de a lermos pelo que escreveu e não pelo que gostaria de ter escrito, como tantas vezes ocorre.

Tal declaração de princípios aponta, se mais não fosse, para a sua aguda consciência do fazer literário, ou seja, para a clara percepção de que a obra literária é um objeto de linguagem, uma obra de arte cuja matéria prima é a própria linguagem. Escreve suas obras como objetos e não como uma exposição de motivos ou opiniões.

E é justamente em sua linguagem - rigorosamente construída, mas dona de dinâmica própria - que residem o diferencial e a inovação dos romances de Dulce Maria Cardoso.

A leitura de seus dois romances, Campo de Sangue (2002) e Os Meus Sentimentos (2005), dos quais o primeiro recebeu, no presente ano, edição brasileira pela Companhia das Letras, coloca os leitores diante de uma ficcionista de rara densidade, sobretudo se for considerada a juventude da autora (nascida em 1964) em relação à verticalidade de sua temática e ao tratamento rigoroso que emanam das estruturas profundas de seus textos.

Em seu romance de estréia, Campo de Sangue, a narrativa se constrói, desde o primeiro fragmento, sobre alicerces aparentemente fugidios em relação ao plano do enredo. O leitor é, no fragmento inicial, convidado a acompanhar, em detalhes, o comportamento de quatro mulheres: elas são postas em confronto, inicialmente, pelo espaço exíguo e constrangedor a que são submetidas pela circunstância em que se encontram. Entretanto, nós, os leitores, não sabemos nada, rigorosamente nada mais do que nos é diretamente colocado por uma linguagem cuidadosa, mas que, sem dúvida, não é a da narrativa tradicional.

Vejamos:

"Estão quatro mulheres na sala. Destas mulheres é preciso saber antes de tudo que estão aqui por causa de um homem que cometeu um crime e que se por acaso se encontrassem na rua não se cumprimentariam.

Esperam. Em silêncio, sem saber o que fazer com as mãos e com os olhos. Ainda que prendam as mãos como às vezes fazem entrelaçando-as sobre o regaço, ou as libertem abandonando-as sobre o banco de madeira, ainda que encontrem um sítio certo para as mãos, sobram os olhos que se desviam uns dos outros, os olhos que, elas sabem, só repousarão se fechados.

Mas as quatro mulheres têm de se vigiar, e por isso soltam os olhos na sala, deixamnos percorrer as paredes, retêm pormenores das paredes, tropeçam no reboco mais rugoso, uma pincelada de tinta mais carregada, uma dedada imperceptível, um insecto esmagado, os olhos ávidos esmiúçam tudo [...]

$\mathrm{Na}$ verdade nenhuma das quatro mulheres quer ou sabe estar nesta sala tão acanhada. Sentem que qualquer voz será despropositada nesta sala desconfortável de luz turva, as quatro mulheres mantêm-se caladas apesar da angústia de ali estarem [...]". (Campo de Sangue, São Paulo: Cia das Letras, 2005, p. 9-10.)

Como se pode notar, as mulheres nos são efetivamente apresentadas, mas de maneira muito peculiar. Há uma instância narradora que, com um olhar rigoroso, de observadora perspicaz, mostra-nos cada uma das personagens. Seus gestos, seus comportamentos, cada um de seus pequenos sinais são colocados em jogo para que o leitor (lançado na 
categoria de leitor ativo, participante) retire do texto seu sentido, ou melhor, algum sentido. Ao leitor é dada a possibilidade de deduzir do que é posto em texto, em linguagem.

Do ponto de vista da técnica narrativa, não nos deparamos, nem provisoriamente, com a apresentação tradicional das personagens, bem como dos outros aspectos constitutivos de uma narrativa como, por exemplo, o tempo ou o espaço. Tais elementos vão-se conjugando e, portanto, produzindo sentidos aos poucos, à medida que são vistos pela instância narrativa e pelo leitor que acompanha a escrita. A questão que se coloca é, portanto, a que leva esse tipo de narrativa. A que veio o romance (como diriam os portugueses) encontramos esclarecido na própria narrativa que, se nós soubermos ler, deixa surpreender sua necessidade e sua razão de ser.

Em Os Meus Sentimentos, o processo de escritura e, por conseqüência, o de escrita é similar. Se as obras são, sem dúvida, diversas entre si, se não se repetem simplesmente, há algumas constantes que, evidentemente, são detectáveis.

"inesperadamente

não devia ter saído de casa, não devia ter saído de casa, não devia ter saído de casa, durante algum tempo, segundos, horas, não sou capaz de mais nada,

inesperadamente paro

a posição em que me encontro, de cabeça para baixo, suspensa pelo cinto de segurança, não me incomoda, o meu corpo estranhamente não me pesa, o embate deve ter sido violento, não me lembro, abri os olhos e estava assim de cabeça para baixo, os braços a bater no tejadilho, as pernas soltas, o desacerto de um boneco de trapos, os olhos a fixarem-se, indolentes, numa gota de água parada num pedaço de vidro vertical, não consigo identificar os barulhos que ouço, recomeço, não devia ter saído de casa, não devia ter saído de casa,

são tão maçadoras as lengalengas" ( $O s$ Meus Sentimentos, Lisboa: ASA, 2005, p. 9.)

Parece-me visível, pela leitura do trecho, que o padrão de escritura se mantém o mesmo. Há, como fica claro, um mesmo narrador rigoroso que observa detalhadamente cada mínimo sinal da cena que se vai compondo, como num passe de mágica, diante dos olhos do leitor.

Mais uma vez preciso recorrer a uma imagem para me fazer entender.

Quando se inicia a leitura de Os Meus Sentimentos, o leitor é lançado no clímax de uma cena que, aos poucos, reconhece como a cena de um acidente automobilístico. Não somos, enquanto leitores, preparados por sumários narrativos que nos situassem previamente em relação ao acidente. Retoricamente, é o recurso ao in media res.

No filme Les Choses de la Vie, dirigido por Claude Sautet, de 1969, também nos deparamos, no primeiro plano da filmagem, com um acidente. À velocidade da narrativa fílmica, contrapõe-se a lentidão densamente significativa da cena inicial da narrativa de Dulce Maria Cardoso. Se o filme, pela seqüência, nos oferece, por conta da velocidade da linguagem cinematográfica utilizada, a clareza de que há um acidente na origem daquela narrativa, em Os Meus Sentimentos o foco é sempre o detalhe, aquilo que vemos através dos olhos da personagem. O que se encontra fora, o exterior, reverbera no interior da personagem e, nós, os fruidores da obra, só por uma leitura ativa, compomos, pelo recorte imagético das metonímias encenadas, a percepção do todo, o próprio acidente. 
Esse processo de escritura implica em um estilo, ou seja, uma forma de escrita: nos dois romances, o que está em jogo não são os acontecimentos em si, mas a discussão dos valores que cada situação humana promove. O texto concita aos leitores, convidados à discussão, realizem por si mesmos uma reflexão acerca dos valores humanos de maneira mais consistente e profunda.

Em Campo de Sangue, o julgamento de um homem (pela justiça dos homens) é a oportunidade para que se enfoquem não as causas superficiais de um crime; não, ainda, seus motores evidentes; nem tampouco a culpabilidade ou inocência daquele que é submetido a julgamento ou a anagnose. $\mathrm{O}$ que está posto em questão é a própria natureza do crime e, por conseqüência, a natureza (criminosa) do ser humano.

No caso de Os Meus Sentimentos, o que é manifesto são os limites entre a vida e a morte, vistos, entretanto, desta nossa margem do rio: a dos vivos. Não há a possibilidade de a vida, mesmo no momento em que se acaba, ou poderia se acabar, ser vista senão a partir da vida. Trata-se de uma impossibilidade lógica.

Portanto, a compreensão do sentido da vida, os limites entre vida e morte, a suspensão do tempo, a impossibilidade de, mesmo diante das condições mais adversas e do provável advento da morte, de se ter a certeza do desenlace são, em Os Meus Sentimentos, a matéria primeira.

Na obra Aparição, de Vergílio Ferreira, há uma questão colocada segundo o enunciado "justificar a vida em face da inverosimilhança da morte" (Aparição, 7ed, Lisboa: Portugália, 1971, p.49). Dulce Maria Cardoso, em Os Meus Sentimentos, de certa for- ma procede à inversão da busca de Vergílio Ferreira. Em última instância, coloca-se, no interior de sua narrativa, exatamente o contrário: como compreender a morte a partir do único modo possível de sua observação, a partir do milagre da vida. Enquanto existência, a vida exclui a morte, a não ser enquanto a vivência da morte alheia, ainda que projetada em nós. Daí a necessidade, pelo rigor de escrita de Dulce Maria Cardoso, de a obra ser concebida como uma obra aberta, como uma narrativa que não se encerra (ainda que finde). Toda a ambigüidade de um final inconcluso aponta para as possibilidades, que se abrem em leque, diante de uma narrativa, que, afinal, apenas fixa algumas visadas sobre a vida, sempre infinita, ainda que aparentemente restrita a um único indivíduo.

Parece ser neste ponto que se encontram, apesar da diversidade aparente, os dois romances de Dulce Maria Cardoso, Campo de Sangue e Os Meus Sentimentos: no estilo da autora.

Já o disse Buffon que o estilo é o homem. Poder-se-ia dizer então que qualquer autor - bom ou mau escritor, com ou sem qualidade literária - o possui. Entretanto, é exatamente o estilo que guarda os traços para que possamos, criticamente, avaliar um autor ou um artista.

E qual é o estilo de Dulce Maria Cardoso? Claro está que não há necessidade de que a autora o saiba conscientemente, embora haja escritores que persigam seu próprio estilo, uma vez encontrado, como a uma fórmula que, muitas vezes, se esvazia.

Em Dulce Maria Cardoso, o estilo é a capacidade, que se transmuta em linguagem criativa de primeiro grau. A marca de estilo da autora é, portanto, a detalhada observação 
de suas personagens, postas inteiramente em situação. Há, como práxis narrativa, um olhar atento, amorosamente colocado em sintonia com as personagens, estabelecendo o livre trânsito entre o seu interior e seu exterior, realizado de tal maneira cuidadosa que o leitor (comum) sequer o detecta. Em sua linguagem, a ausência de marcas de descontinuidade entre os dois universos, colocados em conjunto sem quaisquer barreiras, ou seja, entre o exterior e o interior do homem que, afinal, as personagens evocam, constitui-se em elemento pro- dutor de efeitos de sentido e, portanto, sinais do significativo estilo da autora.

Provisoriamente, portanto, para os limites desta pequena apresentação de uma nova escritora, parece-me ter ficado claro o apelo que os dois primeiros romances de Dulce Maria Cardoso estabelece. Já ouvimos, cariciosamente em nossos ouvidos, as vozes de suas futuras personagens a nos chamar para que nos coloquemos em sintonia com seu próximo romance: que venha logo; já o esperamos!

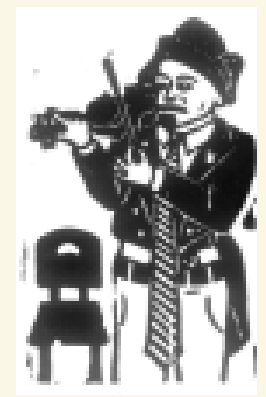

Lesua \& Mela

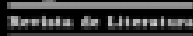

BRIDI, Marlise . Nova voz da ficção portuguesa: Dulce Maria Cardoso. Légua \& meia: Revista de literatura e diversidade cultural. Feira de Santana: UEFS, v. 4, no 3, 2005, p. 261-265. 